\title{
TINGKAT PENGETAHUAN KADER TENTANG SDIDTK DI DESA UMBULMARTANI DAN DESA BIMOMARTANI WILAYAH PUSKESMAS NGEMPLAK I SLEMAN
}

\author{
Christina Ririn Widianti 1
}

${ }^{1}$ STIKes Panti Rapih Yogyakarta, ririnwid@gmail.com

\begin{abstract}
ABSTRAK
Latar Belakang: Anak mengalami pertumbuhan dan perkembangan sesuai dengan tahapannya. Deteksi dini penyimpangan tumbuh kembang perlu dilakukan. Pelaksanaan Stimulasi Deteksi Dini Tumbuh Kembang Anak (SDIDTK) selama ini dilakukan petugas Puskesmas dan para kader kesehatan, tetapi kader tidak rutin melaksanakannya dan cakupan masih rendah.

Tujuan: Tujuan penelitian ini adalah untuk mengetahui tingkat pengetahuan kader tentang SDIDTK di Desa Umbulmartani dan Desa Bimomartani wilayah Puskesmas Ngemplak I.

Metode: Penelitian ini adalah penelitian deskriptif kuantitatif dengan populasi kader di Desa Umbulmartani dan desa Bimomartani. Sampel diambil secara purposive dan dilakukan pada 133 kader.

Hasil: Usia Kader kurang dari separuh adalah berusia 41-50 tahun (44,36\%) dan sebagian kecil berusia 21-30 tahun, sedangkan sisanya berusia 31-40 tahun dan usia 5160 tahun. Pendidikan terakhir Kader menunjukkan bahwa lebih separuh responden berpendidikan SMA $(73,68 \%)$ dan 1 berpendidikan SD. SMP, dan D3. Sebagian besar Kader bekerja sebagai ibu rumah tangga $(87,97 \%)$ dan sisanya bekerja sebagai Guru, Bidan, Wiraswasta, Petani dan PNS. Tingkat pengetahuan Kader tentang stimulasi deteksi intervensi dini tumbuh kembang anak: sebagian kecil memiliki tingkat pengetahuan Kurang $(8,27 \%)$ dan lebih dari separuh $(74,44 \%)$ memiliki tingkat pengetahuan cukup.
\end{abstract}

Simpulan: Tingkat pengetahuan kader tentang SDIDTK masih ada yang kurang sebanyak 8,27\% dan yang cukup 74,44\%

Kata kunci: Pengetahuan, Kader, SDIDTK 


\begin{abstract}
Background: Children experience growth and development according to their stages. Early detection of growth and development deviations needs to be done. The implementation of early detection stimulation for child development (SDIDTK) has been carried out by Puskesmas officers and health cadres, but cadres do not routinely carry out it .
\end{abstract}

Objective: The purpose of this study was to determine the level of knowledge of cadres about SDIDTK in Umbulmartani Village and Bimomartani Village in the Ngemplak I Health Center area.

Methods: This research is a quantitative descriptive study with a population of cadres in the village of Umbulmartani and the village of Bimomartani. Samples were taken purposively and carried out on 133 cadres.

Results: Less than half of the cadres were aged 41-50 years (44.36\%) and a small proportion were 21-30 years old, while the rest were 31-40 years old and 51-60 years old. Kader 's latest education shows that more than half of the respondents have a high school education (73.68\%) and 1 has an elementary education. SMP, and D3. Most of the cadres work as housewives $(87.97 \%)$ and the rest work as teachers, midwives, entrepreneurs, farmers and civil servants. Cadre's level of knowledge about stimulation of early intervention detection of child development and development: a small proportion of them had less knowledge (8.27\%) and more than half $(74.44 \%)$ had sufficient knowledge

Conclusion: The level of knowledge of cadres about SDIDTK was still lacking as much as $8.27 \%$ and sufficient $74.44 \%$

Key words: Knowledge, Cadres, SDIDTK

\section{PENDAHULUAN}

Anak adalah harapan masa depan keluarga dan bangsa. Anak mengalami pertumbuhan dan perkembangan sesuai dengan tahapannya. Pertumbuhan dan perkembangan adalah suatu unit kesatuan yang menggambarkan sejumlah perubahan yang terjadi sepanjang siklus hidup individu. (Wong, et al., 2009).

Tahun-tahun

pertama

kehidupan, terutama periode sejak janin dalam kandungan sampai anak 
berusia 2 tahun merupakan periode yang sangat penting dalam pertumbuhan dan perkembangan anak. Nutrisi yang baik dan cukup, status kesehatan yang baik, pengasuhan yang benar, dan stimulasi yang tepat pada periode ini akan membantu anak untuk tumbuh sehat dan mampu mencapai kemampuan optimalnya sehingga dapat berkontribusi lebih baik dalam masyarakat ( Kemenkes RI, 2016).

Stimulasi yang tepat akan merangsang otak balita sehingga perkembangan kemampuan gerak, bicara dan bahasa, sosialisasi dan kemandirian pada balita berlangsung optimal sesuai dengan umur anak. . Deteksi dini penyimpangan tumbuh kembang perlu dilakukan untuk dapat mendeteksi secara dini adanya penyimpangan tumbuh kembang balita termasuk menindaklanjuti setiap keluhan orang tua terhadap masalah tumbuh kembang anaknya. Apabila ditemukan ada penyimpangan, maka dilakukan intervensi dini penyimpangan tumbuh kembang balita sebagai tindakan koreksi dengan memanfaatkan plastisitas otak anak agar tumbuh kembangnya kembali normal atau penyimpangannya tidak semakin berat. Apabila balita perlu dirujuk, maka rujukan juga harus dilakukan sedini mungkin sesuai dengan indikasi (Kemenkes RI, 2016).

Kegiatan stimulasi, deteksi dan intervensi dini penyimpangan tumbuh kembang balita yang menyeluruh dan terkoordinasi diselenggarakan dalam bentuk kemitraan antara keluarga, masyarakat dengan tenaga profesional akan meningkatkan kualitas tumbuh kembang anak usia dini dan kesiapan memasuki jenjang pendidikan formal.

Program Stimulasi, Deteksi dan Intervensi Dini Tumbuh Kembang (SDIDTK) merupakan salah satu program pokok Puskesmas. Penanggung jawab program SDIDTK di Puskesmas bertanggung jawab mengelola program dan pencapaian tujuan program di Puskesmas. Salah satu pelaksana program SDIDTK adalah seorang kader. Pengetahuan kader mempunyai peranan besar terhadap pelaksanaan SDIDTK.

Wilayah Puskesmas Ngemplak I merupakan wilayah binaan dari Dinas Kesehatan Kabupaten Sleman yang membawahi Desa Umbulmartani, Desa Bimomartani dan Desa Sindumartani. 
Dari hasil wawancara dari petugas Puskesmas, didapatkan data bahwa pelaksanaan SDIDTK selama ini dilakukan petugas Puskesmas dan para kader kesehatan, tetapi kader tidak rutin melaksanakannya. Tidak semua Posyandu memiliki kader yang sudah terlatih SDIDTK. Cakupan SDIDTK di wilayah Puskesmas Ngemplak I terutama untuk Desa Umbulmartani masih rendah dimungkinkan karena Kader belum mengetahui tentang SDIDTK sehingga tidak melakukan SDIDTK . Jika Cakupan Rendah, maka akan sedikit anak yang terdeteksi secara dini jika mengalami gangguan pertumbuhan dan perkembangan.

Berdasarkan fenomena tersebut muncul masalah bagaimana tingkat pengetahuan kader tentang SDIDTK di Desa Umbulmartani dan Desa Bimomartani Wilayah Puskesmas Ngemplak I. Penelitian ini bertujuan untuk mengetahui tingkat pengetahuan kader tentang SDIDTK di Desa Umbulmartani dan Desa Bimomartani wilayah Puskesmas Ngemplak I

\section{METODE PENELITIAN}

Penelitian ini termasuk dalam penelitian deskriptif kuantitatif yaitu suatu metode penelitian yang dilakukan dengan tujuan utama membuat gambaran atau deskriptif yang didasarkan atas perhitungan persentase, rata-rata dan perhitungan ststistik lainnya. Pemilihan sampel dengan tehnik Purposive sampel dengan kriteria kader yang berusia 21-59 tahun, mampu membaca dan menulis serta bersedia menjadi responden. Tehnik pengumpulan data dalam penelitian ini dengan menggunakan angket (lembar kuisioner) yang berisi pertanyaan tentang SDIDTK. Data yang didapat dianalisis univariat.

\section{HASIL DAN PEMBAHAS}

Tabel 1

Karakteristik responden $(\mathrm{n}=133)$

\begin{tabular}{l|c|c|}
\hline \multirow{2}{*}{ Responden } & \multicolumn{2}{|c|}{ Total Responden } \\
\cline { 2 - 3 } & $\mathrm{f}$ & $\%$ \\
\hline a. Responden & & \\
berdasarkan usia & & 6,77 \\
21-30 tahun & 9 & 26,31 \\
$31-40$ tahun & 35 & 44,36 \\
$41-50$ tahun & 59 & 22,55 \\
51-60 tahun & 30 & \\
& & \\
b.Responden & & \\
berdasarkan & & 1,50 \\
Pendidikan & 2 & 12,78 \\
SD & 17 & 73,68 \\
SMP & 98 & 4,51 \\
SMA & 6 & 7,52 \\
D3 & 10 & \\
Sarjana & & \\
& & \\
c. Responden & & 87,97 \\
berdasarkan & & 2,25 \\
Pekerjaan & 117 & 0,75 \\
IRT & 3 & 3,76 \\
Guru & 5 & \\
Bidan & 5 & \\
Wiraswasta & & \\
Petani & & \\
\hline
\end{tabular}




\begin{tabular}{|c|c|c|}
\hline PNS & 2 & 1,50 \\
\hline
\end{tabular}

Hasil penelitian menunjukkan bahwa usia responden terbanyak adalah responden yang berusia 41-50 tahun sejumlah 59 responden $(44,36 \%)$ atau kurang dari separuh, dan sebagian kecil berusia 21-30 tahun sejumlah 9 responden $(6,77 \%)$, sedangkan sisanya berusia 31-40 tahun sejumlah 35 responden $(26,31 \%)$ dan usia 51-60 tahun sejumlah 30 responden ( $22,55 \%)$. Berdasarkan hasil penelitian, responden dalam hal ini kader paling banyak berusia 41-50 tahun yang berarti sudah masuk dalam masa dewasa tua sehingga sudah banyak memiliki pengalaman dan sudah matang secara fisik dan psikis. Notoatmojo (2010), mengungkapkan bahwa usia merupakan salah satu faktor yang bisa mempengaruhi tingkat pengetahuan seseorang. Dengan bertambahnya umur seseorang akan menyebabkan perubahan fisik maupun psikologis. Maka dalam penelitian ini dapat diasumsikan bahwa dengan semakin bertambahnya usia kader diharapkan pengetahuan dan pengalaman kader juga akan semakin meningkat termasuk dalam
Sumber Data : Primer

pengetahuan kader tentang stimulasi deteksi intervensi dini tumbuh kembang anak.

Pendidikan terakhir dari responden menunjukkan bahwa lebih dari separuh responden berpendidikan SMA yaitu sejumlah 98 responden $(73,68 \%)$ dan sisanya sebagian kecil berpendidikan SMP sebanyak 17 responden $(12,78 \%)$, SD sebanyak 2 responden $(1,50 \%)$, dan D3 sejumlah 6 responden $(4,51 \%)$.

Berdasarkan hasil penelitian, maka kader paling banyak sudah berpendidikan SMA/ sederajat. Hal ini sesuai dengan pendapat Notoatmojo (2010), yang menyebutkan bahwa tingkat pengetahuan sesorang bisa dipengaruhi oleh tingkat pendidikan seseorang. Semakin tinggi tingkat pendidikan seseorang, maka sesorang akan mudah menerima informasi dan semakin banyak pengetahuan yang dimiliki. Jika seseorang tingkat pendidikannya rendah, maka akan menghambat perkembangan sikap seseorang terhadap penerimaan informasi dan nilai-nilai yang baru. Hal ini dapat disumsikan bahwa semakin 
tinggi tingkat pendidikan kader, maka akan semakin tinggi tingkat pengetahuan kader tentang stimulasi deteksi intervensi dini tumbuh kembang anak. Semakin tinggi tingkat pendidikan kader, akan lebih mudah bagi kader untuk menerima dan mengingat kembali informasi dan pengetahuan yang didapat terutama tentang stimulasi deteksi intervensi dini tumbuh kembang anak.

$$
\text { Responden berdasarkan }
$$
pekerjaannya, sebagian besar sebagai ibu rumah tangga yaitu sejumlah 117 responden $(87,97 \%)$ dan sisanya bekerja sebagai guru $(2,25 \%)$, Bidan $(0,75 \%)$, Wiraswasta $(3,76 \%)$, Petani $(3,76 \%)$ dan PNS 1,50\%.

Berdasarkan hasil penelitian tersebut, sebagian kader bekerja sebagai ibu rumah tangga. Hal ini akan memepengaruhi pengetahuan kader terutama tentang stimulasi deteksi intervensi dini tumbuh kembang anak. Notoatmojo, 2010 mengungkapkan bahwa lingkungan pekerjaan dapat menjadikan seseorang memperoleh pengalaman dan pengetahuan, baik secara langsung maupun tidak langsung.

\section{Tingkat Pengetahuan Responden Tentang SDIDTK}

Tabel 2

Pengetahuan Responden tentang SDIDTK $(n=133)$

\begin{tabular}{lll} 
& \multicolumn{2}{c}{ Frekuensi } \\
\cline { 2 - 3 } Tingkat Pengetahuan & \multicolumn{2}{c}{} \\
\hline 1. Kurang & 11 & 8,27 \\
2. Cukup & 99 & 74,44 \\
3. Baik & 23 & 17,29 \\
\multicolumn{1}{c}{ Jumlah responden } & 133 & 100 \\
\hline
\end{tabular}

Sumber: Data Primer

Hasil Penelitian menunjukkan bahwa lebih dari separuh $(74,44 \%)$ Responden memiliki tingkat pengetahuan cukup dan sebagian kecil memiliki tingkat pengetahuan Kurang $(8,27 \%)$ dan tingkat pengetahuan baik $(17,29 \%)$. Tingkat pengetahuan Kader yang rendah karena pengetahuan yang kurang dan belum pernah mengikuti pelatihan SDIDTK. Hal ini sesuai dengan pendapat Notoatmojo yang menyebutkan bahwa pengetahuan merupakan hasil dari tahu yang terjadi setelah seseorang melakukan pengindraan terhadap suatu obyek tertentu. Pengindraan terhadap suatu obyek melalui pancaindra manusia, yaitu indera penglihatan, pendengaran, 
penciuman, rasa dan raba. Sebagian besar pengetahuan manusia diperoleh melalui mata dan telinga.

Tingkat pengetahuan 11 kader yang masih kurang perlu mendapatkan perhatian. Untuk tingkat pendidikan mereka ada yang dari SD, SMP maupun SMA dan sudah lebih dari satu tahun menjadi kader. Kemungkinan tingkat pengetahuan mereka masih rendah karena mereka belum mendapatkan informasi pengetahuan tentang SDIDTK baik secara langsung dengan mengikuti pelatihan maupun dengan membaca buku dan mengakses informasi yang berhubungan dengan SDIDTK. Kader memiliki pengetahuan yang cukup tentang stimulasi deteksi intervensi dini tumbuh kembang anak, hal ini kemungkinan karena kader telah memperoleh informasi tentang stimulasi deteksi intervensi dini tumbuh kembang anak. Kader mungkin sudah pernah memiliki pengalaman dalam mengikuti pelatihan tentang stimulasi deteksi intervensi dini tumbuh kembang anak dan mungkin sudah pernah melakukannya dalam setiap kegiatan posyandu. Selain itu, Pengetahuan kader tentang stimulasi deteksi intervensi dini tumbuh kembang anak bisa juga dipengaruhi oleh Usia, pekerjaan dan tingkat pendidikan terakhir yang didapat oleh kader.

\section{KESIMPULAN DAN SARAN}

Kesimpulan

Berdasarkan hasil penelitian Tentang pengetahuan Kader Tentang stimulasi deteksi intervensi dini tumbuh kembang anak di Desa Umbulmartani dan Desa Bimo martani, Maka peneliti dapat membuat kesimpulan bahwa :

a. Kader terbanyak adalah Kader yang berusia 41-50 tahun sejumlah 59 responden $(44,36 \%)$ atau kurang dari separuh, dan sebagian kecil berusia 21-30 tahun sejumlah 9 Kader $(6,77 \%)$, sedangkan sisanya berusia 31-40 tahun sejumlah 35 Kader $(26,31 \%)$ dan usia 51-60 tahun sejumlah 30 Kader (22,55\%).

b. Pendidikan terakhir dari Kader menunjukkan bahwa lebih dari separuh responden berpendidikan SMA yaitu sejumlah 98 Kader $(73,68 \%)$ dan sisanya sebagian kecil berpendidikan SMP sebanyak 17 Kader $(12,78 \%)$, SD sebanyak 2 
Kader (1,50\%), dan D3 sejumlah 6 Kader $(4,51 \%)$.

c. Sebagian besar Kader bekerja sebagai ibu rumah tangga yaitu sejumlah 117 responden $(87,97 \%)$ dan sisanya bekerja sebagai guru (2,25\%), Bidan $\quad(0,75 \%)$, Wiraswasta $(3,76 \%)$, Petani $(3,76 \%)$ dan PNS 1,50\%.

d. Tingkat pengetahuan Kader tentang stimulasi deteksi intervensi dini tumbuh kembang anak: lebih dari separuh $(74,44 \%)$ Kader memiliki tingkat pengetahuan cukup dan sebagian kecil memiliki tingkat pengetahuan Kurang $(8,27 \%)$ dan tingkat pengetahuan baik $(17,29 \%)$

\section{Saran}

a. Untuk peneliti lain: melanjutkan penelitian tentang pengaruh pelatihan SDIDTK terhadap tingkat pengetahuan kader

b. Untuk Puskesmas Ngemplak I : memberikan pelatihan SDIDTK bagi semua kader posyandu Balita

c. Untuk kader : meningkatkan pengetahuan dengan mengikuti pelatihan yang ada tentang SDIDTK dan mempraktekkan pada saat pelaksanaan posyandu.

\section{DAFTAR PUSTAKA}

Adriana, Dian. 2017. Tumbuh Kembang dan Terapi Bermain Pada Anak. Jakarta: Salemba Medika

Aticeh, Maryanah, Sri Sukamti, 2015, Jurnal IImu dan Teknologi Kesehatan, Pengetahuan Kader meningkatkan Motivasi dalam Melakukan Deteksi Dini Tumbuh Kembang Balita, Vol.2, Nomor 2, Maret 2015.

Cahyaningrum, Mawarni. 2015. Viva medika : Gambaran Pengetahuan Bidan Tentang SDIDTK pada Balita Usia 2 Tahun di Banyumas, Volume 08/N omor $15 /$ September/2015

Hockenberry , J. M., \& Wilson, D. 2008. Wong's Nursing Care of Infant and Children. (8 th edition). Canada: Mosby Company.

Kemenkes RI. 2016. Stimulasi, D eteksi dan Intervensi Dini Tumbuh Kembang Anak di tingkat Pelayanan Dasar. Jakarta: Kemenkes.

Notoatmojo, Soekidjo. 2012. Promosi Kesehatan dan Perilaku Kesehatan. Jakarta: Rineka Cipta.

Santrock, John. 2011. Masa Perkembangan Anak, Buku 2, edisi 11, Jakarta: Salemba Humanika. 
Jurnal Keperawatan I CARE, Vol. 1 No. 2 Tahun 2020

Soetjiningsih. 2014. Tumbuh Kembang Anak. Jakarta: EGC.

Supartini, Y. 2014. Buku ajar: Konsep Dasar Keperawatan Anak. Jakarta: EGC.

Wong, et all. 2009. Buku Ajar Keperawatan Pediatrik Wong, Edisi 2, Jakarta: EGC. 